\title{
Sentidos sobre ser professor: a escola do professor-pioneiro em Cláudia-MT*
}

\author{
Senses about to be a teacher: pioneer-teacher's school in Claudia city, \\ Mato Grosso State
}
Sentidos sobre ser profesor: la escuela del profesor-pionero en Cláudia, Estado de Mato Grosso

CRISTINNE LEUS TOMÉ**

\begin{abstract}
RESUMO - Este artigo é resultado da pesquisa realizada na cidade de Cláudia, Mato Grosso, cuja proposta foi investigar como os professores construíram a história do sistema educacional em suas práticas pedagógicas na primeira década (1978-1988) de colonização e que sentidos deram à educação. Com o aporte teórico da Análise de Discurso pêcheuxtiana, levantaram-se efeitos de sentido sobre o ensino público, o papel do professor-pioneiro e a escola que se formou dentro deste contexto. Conclui-se que a escola do professor-pioneiro foi resultado de uma luta política que se estabeleceu entre a comunidade e o poder público. A comunidade participou construindo a escola e indicando moradores para que trabalhassem como professores enquanto o poder público fornecia material didáticopedagógico, assessorava e qualificava os professores em sala de aula.
\end{abstract}

Palavras-chave - Educação. Ensino público. Professor-pioneiro. Análise de discurso.

\begin{abstract}
This article is the result of a research developed in the city of Claudia, Mato Grosso State. It aimed to investigate howteachers from that city built the history of the educational system in their teaching practices in the first decade (1978-1988) of colonization. The text also shows the senses teacher gave to education. With the theoretical framework of Discourse Analysis, according to Pêcheux, the research rose meaning senses on public education, the role of the pioneer-teacher and the school within that context. We concluded that the pioneer-teacher's school was the result of a political struggle developed between the community and the public power. The community built the school and it indicated residents to work that as teachers. The government supplied textbooks teaching, advising and qualified teachers in the classroom.
\end{abstract}

Keywords - Education. Public education. Pioneer-teacher. Discourse analysis.

RESUMEN - Este artículo es el resultado de la investigación en la ciudad de Claudia, Mato Grosso, cuyo propósito era investigar cómo los profesores construyeran la historia del sistema educativo en sus prácticas de enseñanza en la primera década de la colonización (1978-1988). Con el marco teórico de análisis del discurso pêcheuxtiana, se buscó efectos de sentido en la educación pública, el papel del profesor-pionero y de la escuela que se constituyó en este contexto. Se concluye que la escuela del profesor-pionero fue el resultado de una lucha política que se desarrolló entre la comunidad y el gobierno. La comunidad participó en la construcción de escuelas y nombrando los de la comunidad para que trabajaran como profesores, mientras que el gobierno proporcionó los materiales de enseñanza, asesoramiento y cualificación de los profesores en el aula.

Palabras clave - Educación. Educación pública. Profesor-pionero. Análisis del discurso.

\footnotetext{
*Este artigo é um recorte da tese em Educação (2004-2009) em que se investigou o processo da escolarização na cidade de Cláudia - Mato Grosso.

**Doutora em Educação pela Universidade Federal do Rio Grande do Sul (Porto Alegre, RS, Brasil) e professora na Universidade do Estado de Mato Grosso

(Cáceres, MT, Brasil).E-mail: <cristinne@unemat-net.br>.
} 


\section{INTRODUÇÃO}

Neste artigo abordaremos o processo de escolarização na cidade de Cláudia - Mato Grosso, entre os anos 1978 e 1988, a partir de quatro entrevistas realizadas com professores que lecionavam na época. Tivemos como objetivo compreender os sentidos que eles deram à educação a partir de suas práticas pedagógicas e como se constituiu a escola do professor-pioneiro. Para tanto, levantamos o contexto histórico do processo de escolarização: escolha das localidades, construção predial e fundação das escolas, seleção dos professores, abordagens didático-pedagógicas, política de adequação entre o poder público e a comunidade para que as escolas funcionassem.

O processo de escolarização em Cláudia esteve vinculado ao contexto geopolítico em que se encontrava a cidade e suas sequentes divisões municipais que ocorreram dentro do Estado do Mato Grosso. Primeiramente, quando Cláudia pertencia ao Município de Chapada dos Guimarães (entre os anos de 1978 e 1979), a escolarização iniciou com a instalação da escola estadual no centro da cidade. $\mathrm{Na}$ década de 80 , já pertencendo ao Município de Sinop, criou-se em Cláudia uma rede de escolas públicas municipais rurais, de $1^{\mathrm{a}}$ a $4^{\mathrm{a}}$ série, cujo objetivo era fornecer condições de estudo aos filhos dos novos imigrantes nas áreas mais distantes do núcleo urbano central.

Nos anos 1970, municípios recém-formados foram estabelecidos no norte mato-grossense com base em políticas públicas econômicas que tinham por objetivo a colonização no interior do Brasil. O Projeto da Gleba Celeste, ao qual se inseria Cláudia, tinha uma área de colonização constituída "de quatro núcleos coloniais: a Cidade de Vera (instalada em 27 de julho de 1972); a Cidade de Sinop (instalada em 14 de setembro de 1974); a Cidade de Santa Carmem (instalada em 15 de setembro de 1974) e a Cidade de Cláudia (instalada em 1978)" (SOUZA, 2004, p. 124).

A Colonizadora Sinop S.A., proprietária das terras e do Projeto da Gleba Celeste, mantinha um programa de colonização incentivando a vinda de imigrantes para essas novas cidades. As terras foram cortadas, os centros urbanos mapeados e os imigrantes chegavam de maneira constante, vindos da Região Sul do país. Os primeiros imigrantes passaram a ser conhecidos como pioneiros, tanto nas falas das pessoas quanto nos documentos oficiais. $\mathrm{O}$ atributo pioneiro tornou-se uma regularidade nos discursos promovidos pelas instituições públicas e privadas. Inicialmente, a palavra pioneiro circulou em documentos da Colonizadora Sinop em suas publicações a partir de 1972. No texto "Histórico da Gleba Celeste $-5^{\text {a }}$ parte Cidade de Cláudia" (s.d., 5 fls.), em que apresenta uma sinopse sobre o projeto de colonização, o substantivo "pioneirismo", correlato de pioneiro, aparece para caracterizar a empresa dona e responsável pelas terras adquiridas:

A experiência da colonização da GLEBA CELESTE $5^{\text {a }}$ PARTE, é, para a COLONIZADORA SINOP S.A., muito mais do que a reedição de tantos passos que já deu, e conquistas, desbravamentos, pioneirismo e criação de núcleos rurais e cidades no interior brasileiro, principalmente no Norte Paranaense, e agora, no norte do Estado de Mato Grosso (s.d., fl. 01).

A partir dos documentos oficiais, o sentido de empresa pioneira transpassa a perspectiva do setor empresarial e se assenta, também, na perspectiva dos colonizadores os quais ela incentivou para ali chegarem; seus moradores também são apresentados como os pioneiros.

Como exemplo, temos na revista on-line MTNews (2004, p. única) um pequeno histórico sobre a cidade de Cláudia. O adjetivo pioneiro, em "ato pioneiro", associado à empresa Colonizadora, é deslocado aqui para os moradores que foram colonizar a cidade de Cláudia, sendo eles os "primeiros".

A 25 de maio de 1978 chegavam à região os irmãos Maldonado, que fundaram a Madeireira Cláudia Ltda. Num ato pioneiro vieram também os primeiros moradores, trazendo a tiracolo suas famílias, vindas especialmente do estado do Paraná, e estabeleceram na futura cidade de Cláudia.

Textos da época, documentos oficiais, reportagens e falas dos primeiros moradores e professores apontam um conjunto de fatores que, em dado contexto histórico, $\mathrm{o}$ adjetivo pioneiro passou a ser considerado como uma designação, isto é,

[...] o que se poderia chamar de significação de um nome, mas não enquanto algo abstrato. Seria a significação enquanto algo próprio das relações de linguagem, mas enquanto uma relação linguística (simbólica) remetida ao real, exposta ao real, ou seja, enquanto uma relação tomada na história (GUIMARÃES, 2002, p. 9).

A designação pioneiro como uma "relação tomada na história" se estende aos locais de trabalho destes pioneiros, como as escolas-pioneiras. A construção das escolas para os filhos destes pioneiros passou a ser mais uma das prioridades públicas, uma vez que tinha como objetivo imediato fixar estes imigrantes na localidade. O próprio Plano de Loteamento da cidade de Cláudia previa a construção de escolas, o que se caracterizava como um chamariz, incentivando gaúchos, catarinenses e, principalmente, paranaenses a se mudarem para Cláudia. Os imigrantes, ao adquirirem suas propriedades de terras 
ou lotes no centro urbano, já contavam com as escolas para a educação de seus filhos.

\section{O PLANO DE LOTEAMENTO: SENTIDOS SOBRE A ESCOLA}

O projeto da Colonizadora para a Gleba Celeste previa o corte das terras em lotes urbanos e rurais, vendidos aos imigrantes através do pagamento à vista ou a prazo pelo Banco do Brasil. Este plano foi autorizado pelo INCRA, pelo Decreto $n^{\circ} 18$, em 1972, mesmo ano em que se iniciou a venda das terras para colonização (SOUZA, 2004). Em Cláudia, especificamente, a estrutura urbana foi dividida em setores, com a área residencial e comercial e a área industrial. No documento Plano de Loteamento de 1983 (Colonizadora Sinop S.A.), destacamos o ponto sobre a economia e a educação, buscando efeitos de sentido a respeito dessa relação. Com o título Plano de Conjunto: Atividades Agropecuárias, Comerciais, Industriais e Sociais, temos o seguinte texto:

A agropecuária está desenvolvida, destacando-se a atividade hortigranjeira.

Cidade CLÁUDIA, de porte médio, prevista para abrigar população de 23.000 almas, vive de produtos agrícolas, de indústrias de madeira e pequeno comércio.

Os aspectos cultural e social têm ultrapassado as nossas previsões. As escolas encontram-se em plena atividade, e a orientação do ensino segue, rigorosamente, a moderna programação.

O discurso propagado à época entre a população sulista era de que a "agropecuária está desenvolvida" destacandose a produção hortigranjeira, o comércio, e a indústria da madeira, serrarias e madeireiras para beneficiamento. Os imigrantes que ali chegavam participariam de uma sociedade que lhes propunha uma possibilidade de empregos futuros junto à terra, em pequenos comércios ou como trabalhadores na indústria madeireira, a indústria que mais trabalhadores empregava.

Para "Os aspectos cultural e social" da cidade de Cláudia, o único exemplo de vida cultural e social era a escola. E, agora, temos a expressão "cultura", não no sentido de conhecimentos para a lida na terra, mas como possibilidades de conhecimentos outros, de ampliação dos horizontes com vistas às "“coisas a saber', conhecimentos a gerir e a transmitir socialmente" (PÊCHEUX, 2002, p. 34). O Plano de Loteamento coloca que, neste aspecto, "têm ultrapassado as nossas previsões", uma vez que "As escolas encontram-se em plena atividade e a orientação do ensino segue, rigorosamente, a moderna programação". Esse texto é de 1983, quando tínhamos a escola estadual e sete escolas municipais rurais.
Ter uma "moderna programação" escolar, em uma cidade de 2.300 habitantes, espalhados em uma extensão territorial de $113.146,8470$ hectares, nos leva a refletir sobre a importância de se ter o mais moderno, mesmo quando distante de um centro cultural mais importante. Elias (1994, p. 23), ao definir o conceito de civilização, o faz assim:

[...] refere-se a uma grande variedade de fatos: ao nível da tecnologia, ao tipo de maneiras, ao desenvolvimento dos conhecimentos científicos, às ideias religiosas e aos costumes. Pode-se referir ao tipo de habitações ou à maneira como homens e mulheres vivem juntos, à forma de punição determinada pelo sistema judiciário ou ao modo como são preparados os alimentos. Rigorosamente falando, nada há que não possa ser feito de forma "civilizada" ou "incivilizada". Daí ser sempre difícil sumariar em algumas palavras tudo o que se pode descrever como civilização.

O autor destaca que civilização é um conceito que está associado a diferentes fatores e atividades do cotidiano humano, como técnicas, costumes, ideias, que apontam ao modo como a sociedade se organiza para a vida em comum. Quando o autor analisa o conceito de civilização em sua função, ele vai apresentar que este se encontra em "descrever o que lhe constitui o caráter especial e aquilo de que se orgulha: o nível de sua tecnologia, a natureza de suas maneiras, o desenvolvimento de sua cultura científica ou visão do mundo, e muito mais" (Ibid., grifo do autor). Cada nação partiu do seu ponto de vista para reconhecer no outro a forma civilizada ou incivilizada; assim, a medida de considerar algo como civilizado ou não está na dependência do ponto de vista de quem nomeia.

E a escola também seguia a sua "programação moderna". "Rigorosamente", se promovia a inserção de Cláudia como uma cidade moderna, cultural e com uma população educada. A escola como fonte de cultura e conhecimento, como envolvimento social, promove a ideia do "moderno", do novo, do progresso, ampliando as possibilidades de coisas a fazer para os moradores, alargando os horizontes de coisas a pensar. $\mathrm{O}$ processo civilizatório em Cláudia, no que se refere à produção de conhecimentos, à manufatura de materiais, ao aprendizado de artes diversas, teve na escola uma instituição importante, um aliado. Mutti (2005, p. única), sobre as práticas discursivas escolarizadas manifestas na escola, discorre que:

A sociedade legitimou essa instituição para tratar da educação sistematizada e hierarquizada. Na instituição escola, desenvolvem-se práticas discursivas que são protagonizadas por sujeitos, tendo como um objetivo 
primordial a conservação do acervo de conhecimentos. Esses conhecimentos, que fazem parte dos currículos, ali constam porque já sofreram um processo de validação, o que significa que sempre existem conhecimentos excluídos desse conjunto.

Uma escola "moderna", com currículo validado, foi o palco de trabalho de nossos professores. Neste ponto levantamos a questão: que sentidos os professorespioneiros dão para esta escola; como era a escola do professor-pioneiro?

A cidade de Cláudia recebeu seus primeiros imigrantes em 1978, ano da chegada da primeira professora, Roseli de Moura Maldonado, que nos falou: "Daí chegou o mês de março de 79 , e não aparecia ninguém para ser professora". Como não havia escolas na cidade, ela iniciou o movimento que resultou na instalação da escola estadual. A educação, a partir desse momento, teve sempre como características e fronteiras as condições sociais, econômicas e culturais das pessoas que para ali migraram.

O mapa escolar da cidade de Cláudia foi se constituindo em duas áreas separadas: o centro urbano, com a escola estadual, e a zona rural, com as escolas municipais. Além da divisão geográfica, o quadro docente também apresentava características distintas. Enquanto a escola estadual se destacava por ter professores mais qualificados, ou com possibilidade de qualificação e por trazer para trabalhar como professores os bacharéis que havia na cidade, como o médico, o engenheiro e o arquiteto, nas escolas municipais sobressaía um quadro mais comprometido, dependendo dos próprios interessados e de seus vizinhos, moradores dos sítios ou empregados das madeireiras para atuarem como professores. Se compararmos ao quadro da escola estadual, a escola municipal estava em desvantagem quanto à qualificação de seus profissionais. Apesar de haver períodos de contratação de professores com qualificação precária também na escola estadual, notamos que a escola municipal rural esteve mais à mercê desta contingência, com a maioria de seus professores não tendo completado o $1^{\circ}$ grau. As pessoas da comunidade que se candidatavam para atuar como professores em uma escola municipal realizavam um curso didático preparatório em Sinop e, a seguir, eram alocados em uma sala de aula.

As escolas municipais rurais foram criadas na modalidade educacional multisseriada e, a partir disso, possibilidades de seriação foram implantadas conforme o número de matrículas realizadas e a disponibilidade de espaço para a sala de aula. Tinham como característica serem construídas em núcleos de povoamento rural, geralmente em encruzilhada, em área de sítios, ou em firma madeireira. As escolas municipais ligadas às madeireiras, núcleo de pioneiros industriais, existiram tomando por base duas características fundamentais: para a fixação do empregado à firma e por ser uma exigência legal. A escola construída nestes locais resolvia o problema da evasão de funcionários (por não haver escola para os filhos) e, ao mesmo tempo, disponibilização do acesso à escolarização dos filhos dos proprietários das firmas. Apesar de estarem dentro dos domínios das fábricas, as escolas eram abertas a toda a comunidade.

\section{Confrontando POSIÇÕES: O SUJEITO PROFESSOR-PIONEIRO SE CONSTITUI}

A posição-sujeito pioneiro encontra-se entre o identificar-se com o presente (situação presente, o novo real que se apresenta) e desidentificar-se com o passado (situação passada, o antigo modelo de vida), em um efeito pendular que busca o equilíbrio, uma vez que a nova posição-sujeito estabelece um confronto entre as duas situações, entre o identificar-se e o desidentificarse. Sobre a identificação/desidentificação do sujeito, Pêcheux abordou a relação do sujeito em suas Formações Discursivas (FD), teorizando que a interpelação do indivíduo em sujeito mobiliza, heterogeneamente, confronto de posições e sentidos diferentes que afloram ao sujeito no momento da interpelação. Supõe-se, assim, que a identificação do sujeito ao discurso promova um

\begin{abstract}
desdobramento, que pode assumir diferentes modalidades: a primeira consiste [em] uma superposição entre o sujeito da enunciação e o sujeito universal [...] (o interdiscurso determina a formação discursiva com a qual o sujeito, em seu discurso, se identifica, sendo que o sujeito sofre cegamente essa determinação, isto é, ele realiza seus efeitos "em plena liberdade"), [...] discurso do "bom sujeito"; [...] a segunda modalidade caracteriza o discurso do "mau sujeito", discurso no qual o sujeito da enunciação "se volta" contra o sujeito universal por meio de uma "tomada de posição", que consiste em "uma separação (distanciamento, dúvida, questionamento, contestação, revolta...)", [...] o "mau sujeito" se contraidentifica com a formação discursiva que lhe é imposta pelo "interdiscurso" como determinação exterior de sua interioridade subjetiva, [...] o que produz o contradiscurso. Estas modalidades levam a uma terceira, a desidentificação, que constitui um trabalho (transformação-deslocamento) da formasujeito (PÊCHEUX, 1995, p. 213-217).
\end{abstract}

Com base nessa transcrição, temos um sujeito dividido, em que, "por meio de uma tomada de posição" ele se desloca, se movimenta dentre as formações discursivas as quais assume. Na primeira modalidade, discurso do bom sujeito, há "uma superposição" "em plena liberdade", em que o sujeito do discurso se identifica com a forma-sujeito da formação discursiva que o constitui. Na segunda 
modalidade, discurso do mau sujeito, há uma reviravolta, o sujeito do discurso se "distancia", "se volta" contra a formação discursiva que o afeta, "questiona" os saberes impostos pelo interdiscurso.

Entendemos que sujeito-pioneiro, sujeito do discurso, é conduzido a contraidentificar-se com os saberes da formação discursiva que o afetava antes de migrar para Cláudia. Ao reproduzirem o mesmo nas novas terras e não colherem os mesmos frutos, foram se "distanciando" dos saberes já dados e impelidos a significar novos olhares sobre esta nova exterioridade.

Para permanecer na nova posição, o sujeito deve romper e desidentificar-se, isto é, não com o apagamento dos saberes já dados, que o assujeitavam na forma-sujeito antiga, mas entender o desidentificar-se a sentidos, quando o sujeito tem que produzir novos sentidos. A desidentificação do sujeito, de sua forma-sujeito e, portanto, também de sua formação discursiva, é deslocada para identificar-se a uma nova forma-sujeito e formação discursiva, no caso, a forma-sujeito professor-pioneiro. Entre um e outro, entre a resistência de identificar-se/ desidentificar-se, há a reprodução quando se desloca uma determinada prática para outro contexto.

O "mau sujeito" rompe e se desidentifica com os sentidos já dados, já estabelecidos quando pequeno proprietário de terra no Paraná, por exemplo, dentro da formação discursiva do agricultor. Ainda dentro da mesma formação discursiva, como agricultor em Cláudia, este sujeito teve que ressignificar os sentidos já dados. Não houve deslocamento da formação discursiva. Os novos sentidos, a "dúvida", o "questionamento", entre a identificação e o contraidentificar-se acontece no interior da formação discursiva. "Isto é: a contraidentificação é um trabalho do sujeito do discurso sobre os dizeres e os sentidos que são próprios à FD que o afeta e, por conseguinte, se institui como forma de resistência à forma-sujeito e ao domínio de saberes que ela organiza" (INDURSKY, 2005, p. 6).

$\mathrm{Na}$ terceira modalidade, temos a desidentificação, "trabalho da forma-sujeito", movimento de transformação e deslocamento. A desidentificação do sujeito, de sua forma-sujeito e, portanto, também de sua formação discursiva, é deslocada para identificar-se a uma nova forma-sujeito e formação discursiva, no caso, a forma-sujeito designada como professor-pioneiro. Entre a resistência de identificar-se/desidentificar-se, há a reprodução quando se desloca uma determinada prática para outro contexto: os imigrantes chegaram, identificados com determinados saberes, afetados por determinadas formações discursivas, e movimentaramse por entre estes já ditos nos momentos iniciais de sua permanência em Cláudia (como a ideia inicial de plantar café, desconhecendo o clima e o solo do Mato Grosso); por meio de uma tomada de posição, foram impelidos a ressignificar seus sentidos (como quando o plantio de café não foi possível). Por motivos econômicos, estes sujeitos tiveram que se deslocar da posição de agricultor e, na realidade de Cláudia, abarcar outra posição possível, como a de trabalhar de professor. Nem todos os sujeitos imigrantes pertenciam à formação discursiva da educação e desconheciam seus saberes, mas foram afetados, assujeitados por ela, e se assumiram na nova posição de professor. $\mathrm{O}$ sujeito, quando fala, adere à sua formação discursiva, se assujeita; é na prática discursiva que esse movimento se mostra.

Quando falamos em formação discursiva, pensamos na associação à noção de forma-sujeito e sua dispersão nas diversas posições-sujeito, isto é, seus lugares sociais. Na prática discursiva deste sujeito, por dentre seus lugares sociais ocupados, é que se constitui como o momento em que o sujeito se inscreve no "complexo contraditóriodesigual-sobredeterminado das formações discursivas que caracteriza a instância ideológica em condições históricas dadas" (PÊCHEUX, 1995, p. 213). Neste "complexo contraditório-desigual-sobredeterminado" o efeito da contradição acontece nas posições do sujeito, seus lugares sociais ocupados, quando do seu relacionamento com sua forma-sujeito, isto é, o sujeito histórico. Na relação entre o intradiscurso e o interdiscurso, na relação entre a língua e a formação discursiva, se realizam as práticas discursivas e neste processo é que se produzem os sentidos históricos como efeitos deste sujeito histórico. Para Pêcheux (1995, p. 213-214; (grifo do autor):

[...] a questão do discurso na forma-sujeito: uma vez que não existe prática sem sujeito [...] a questão da prática discursiva levará necessariamente à questão do efeito do complexo das formações discursivas na formasujeito. Não se trata de dizer, porém, que uma prática (discursiva ou não) seja a prática do sujeito [...] mas sim de constatar que todo sujeito é constitutivamente colocado como autor de e responsável por seus atos (por suas "condutas" e por suas "palavras") em cada prática que se inscreve $[\ldots]$.

Ao ser "colocado como autor", "responsável por seus atos", "em cada prática", nos seus atos cotidianos, que se definem pelas condições de produção do discurso, o sujeito parte da posição imaginária em que se encontra. É desta posição que o sujeito se coloca como se fosse autor, fonte e origem de seu dizer. É na prática discursiva que ele vai ser "responsável por seus atos", vai buscar dar sentidos ao que se mostra e filiar-se aos discursos já dados.

O professor-pioneiro se filia a sentidos heterogêneos, que vêm de discursos sociais ligados à prosperidade econômica, ao trabalho para sobreviver nas dificuldades 
e vencer na vida, aos princípios familiares tradicionais, à união para atingir um objetivo comum, entre outros. Nesse complexo de filiações produz o seu gesto de interpretação no discurso pedagógico, caracterizando a sua posição de professor, na sala de aula e na comunidade. O sujeito está sempre paradoxalmente sendo "colocado como autor de e responsável por"; isto é, nosso sujeito como pertencente a um contexto histórico, em que, por meio de paráfrases e polissemias, ele repete/desloca esses sentidos, buscando controlar, mas também criar sentidos "como autor" e "sendo responsável" quando coloca em funcionamento seu discurso. A partir de sua posição de professor ele se apresenta em condição de significar. O professor-pioneiro se filia ao discurso pedagógico e se sujeita a ele, se filia/é filiado aos sentidos que constitui/é constituído, passando a significar o seu dizer a partir da posição dada.

Para estudarmos a posição de sujeito-pioneiro, nos movemos por procedimentos analíticos em que cabe "detectar os momentos de interpretação", "através das descrições das 'montagens discursivas'." São, pois, dois movimentos: descrição e interpretação, os quais, embora distintos, são muito próximos. Segundo Pêcheux (2002, p. 57):

[...] supõe somente que, através das descrições regulares de montagens discursivas se possam detectar os momentos de interpretações enquanto atos que surgem como tomadas de posição, reconhecidas como tais, isto é, como efeitos de identificação assumidos e não negados.

Entre o identificar-se e o desidentificar-se, a posição de sujeito assumida por esse pioneiro poderia ser indicada como trabalhador-pioneiro; seria uma posição de certo modo aberta a trabalhos vários, que abrigou também a possibilidade de trabalhar como professor.

Tendo em vista o sentido de improvisação que veio junto com o posicionamento como sujeito-professor, esse professor-pioneiro não se isentou de caracterizar-se como um trabalhador pouco qualificado para exercer a função. Restou-lhe a condição de aprender a ser professor a partir do enfrentamento dos desafios da prática, cheia de carências bem-acentuadas. Cabe lembrar as precariedades relacionadas ao espaço físico-geográfico inóspito, à falta de infraestrutura institucional, à falta de formação dos profissionais para o trabalho de professor, às dificuldades das famílias-pioneiras para conseguir proporcionar estudo aos filhos.

O sujeito trabalhador-pioneiro passou a constituirse como professor-pioneiro, tomou essa posição e se identificou, interpretando esta "tomada de posição". Essa filiação surgiu como "efeito de identificação" ao lugar de professor no discurso pedagógico. De imigrante que queria tornar-se proprietário de terra a professor, este pioneiro, ao assumir-se como professor, se desloca também para se aprimorar e bem desempenhar os encargos da nova posição ou, pelo menos, para cumprir a obrigatoriedade de formar-se para trabalhar como tal.

Ao chegar a Cláudia, ele se tornou um estudante desta nova realidade, ressignificou este mundo novo e buscou o seu trabalho, o seu lugar. "Detectar os momentos de interpretações enquanto atos que surgem como tomadas de posição", citado anteriormente, demanda um movimento simbólico de identificação: o sujeito, de dentro da formação discursiva, ou da rede de sentidos socialmente constituída, assume a sua identificação como professorpioneiro e responsável por suas condutas na sua escola.

\section{A ESCOLA DO PROFESSOR-PIONEIRO}

A escola do professor-pioneiro partiu do desejo manifestado em recriar na nova moradia, em Cláudia, uma situação similar à antiga, ponto de ressignificações entre os sentidos: antigos e novos chocam-se, alguns se mantêm enquanto outros são construídos, em um gesto de "tomada de posição". Neste momento temos os moradores defendendo seus interesses frente ao poder público e organizando-se para estabelecer a escola entre eles. Dentre as tantas práticas cotidianas, a instituição escolar é representativa desde o início da colonização de Cláudia. Para ela converge a organização social para seu estabelecimento, a organização espacial de construção, a organização das atividades que nela serão desenvolvidas, como as pessoas que ocuparão a posição de professor, a posição de aluno, a função de cada uma e o seu lugar.

As primeiras escolas municipais, a princípio, foram construídas e mantidas pelos moradores, feitas a partir de armações de varas cobertas com lona ou com folhas, sob o chão batido. Na fala do professor Vilson Vollbrecht, ao descrever a escola em que trabalhou sua esposa, a professora Iris Gujahr Vollbrecht, coloca que era "fechada com ripas de coqueiros. Era uma escola totalmente coberta por lâmina e lona plástica". Os professores-pioneiros se sujeitaram ao trabalho em condições físicas irregulares, e até perigosas, porque já experimentavam estas condições com suas famílias, pessoalmente ou por meio de conhecidos. Os professores contam que, no início, tiveram que morar em barracas improvisadas enquanto aguardavam a mudança para a casa definitiva. Morar em habitações provisórias era parte das dificuldades encontradas pelos imigrantes, e para o professor-pioneiro não seria diferente: dentre as primeiras escolas também houve as que tiveram um início mais dificultoso que outras, sendo um motivo de união entre os professores para permanecerem juntos reivindicando melhores condições para o fazer pedagógico. 
Estes professores imigrantes, estes sujeitos que ali chegaram, ao se assumirem como professores, produziram novas imagens sobre si e sobre o objeto simbólico escola. Para Pêcheux (1997, p. 82), é possível compreender que os sujeitos, dentro de processos discursivos de significação, "o que funciona nos processos discursivos é uma série de formações imaginárias que designam o lugar que [entre eles] se atribuem cada um a si e ao outro, a imagem que eles se fazem de seu próprio lugar e do lugar do outro". Essa nova imagem, como professor, o autorizava a pleitear novas construções para as escolas, por exemplo.

A cobrança para o fornecimento de materiais de construção junto ao Departamento de Educação ou à Secretaria de Educação, para a construção das escolas municipais era uma constante. O mesmo ocorria com a escola estadual, em que o apoio recebido vinha da Colonizadora Sinop S.A., em forma de terreno e edificação. A partir do empenho dos professores, a comunidade se reunia para angariar fundos, promovendo festas e eventos visando à construção de novas salas de aula.

A escola do professor-pioneiro era uma representante da discursividade nas relações sobre o poder. Ao mesmo tempo em que os professores cobravam das autoridades mais escolas, a presença do Estado se fazia presente, por meio das Secretarias de Educação, Municipal e Estadual, na pessoa de seus supervisores de ensino que constantemente visitavam seus professores, verificavam as condições de ensino, a capacidade de ensinar dos professores e a opinião da comunidade.

$\mathrm{Na}$ escola municipal, os professores recebiam seu material diretamente do Departamento ou Secretaria de Educação com o elenco dos conteúdos a serem ministrados. Os alunos realizavam provas bimestrais e uma avalição geral ao final do ano visando à aprovação para a série seguinte. $O$ professor dividia sua turma única em quatro séries e tinha como atividades diárias ministrar as aulas, limpar a sala e cozinhar para os alunos. Periodicamente, os supervisores escolares circulavam pelas escolas municipais para verificar e avaliar o trabalho do professor junto aos alunos. Quando, por algum motivo levantado pela comunidade, pelos alunos ou pelo professor, a supervisão era chamada, um debate era formado avaliando a situação a fim de reverter o quadro. Fazia-se necessário verificar as informações para que a supervisão pudesse tomar as decisões imediatamente. Nesta relação discursiva entre os representantes da escola e da supervisão se constituía a imagem do ser professorpioneiro como um sujeito marcado pela heterogeneidade, com um discurso atravessado pela comunidade e pela supervisão. A sala de aula do professor-pioneiro era uma maneira de o afetar e, assim, comprometer-se com as relações interpessoais e com o processo de significações ideológicas.
Na fala do professor João Olegário dos Santos, que representava a comunidade das escolas rurais de Cláudia junto ao Município de Sinop, temos que ele próprio assumiu o compromisso de conseguir estabelecer escolas na zona rural para seus moradores, conseguir material para seus alunos e apoio pedagógico para preparar os professores iniciantes.

\begin{abstract}
João Olegário: $\mathrm{Eu}$, na verdade, trabalhei nessa Escola, em 82 e 83, como professor, nessa Escola. [...] Aí, no final do mês, eu vim pra Sinop, consegui mais alguns livros, com a professora Olga, e ela me repassou esses livros. [...] A a professora Olga passou a acompanhar. [...] eu terminei aquele ano, em 84, que eu me transferi para essa Escola Dilma, já, também, a pedido da direção da escola, aqui em Sinop, ainda no comando da professora Olga, que era a diretora pedagógica e, depois, naquele ano, ela já tinha transformado como Secretaria de Educação. Ela passou a ser Secretária de Educação. E a Olga gostou muito do meu trabalho, segundo ela dizia, são palavras dela, ela dizia, assim, que, ela chegou até a falar uma vez pra mim: "João, tem gente que se faz professor, tem gente que nasce professor, você nasceu professor". Eu acho, assim, que o seu trabalho é muito bom. Ela usava muito, às vezes, em reunião, nossa! Exemplos da forma que eu resolvia os problemas na escola. Porque sempre se tem probleminha com aluno, probleminha com pai, e eu contornava. Então, jamais eu trazia problema para ela, para cá [em Sinop, onde ficava a Secretaria de Educação], eu resolvia, eu chegava aqui e falava: "Ó, Olga, aconteceu isso, isso, e isso na escola e eu resolvi dessa forma." "Ah, muito bem, João, é assim mesmo, é assim que você tem que fazer." Aí, eu passei a atuar na Dilma [...].
\end{abstract}

Nosso olhar analítico, ao procurar investigar as práticas discursivas do professor-pioneiro, levanta este exemplo de controle na repetição em paráfrase das frases da professora Olga Ribeiro Gomes: "João, tem gente que se faz professor, tem gente que nasce professor, você nasceu professor." "E, e eu acho, assim, que o seu trabalho é muito bom." A professora Olga, como responsável e autoridade na Secretaria de Educação, tinha, em analogia entre um e outro, o controle e o poder de/sobre seus professores. Como responsável, o controle para averiguar a falta de suprimentos alimentícios, produtos de limpeza, materiais de uso diário para o professor, como giz e livros, por exemplo. Como autoridade, ela detinha o poder para julgar as ações de seus professores em suas atividades na sala de aula: "O seu trabalho é muito bom", dizia ela ao professor João Olegário. Ela era a responsável para que esta instituição escola se firmasse no local e cumprisse com o seu papel de qualificação dos alunos. 
$\mathrm{Na}$ concepção da supervisão escolar, o objetivo era estabelecer um princípio possível de ensino com base em um quadro de imigrantes não qualificados para exercer essa atividade. A partir dessa premissa, as instâncias que envolviam seu corpo docente eram todas acompanhadas, famílias dos alunos e a escola. Conseguir pessoas para atuar como professores, qualificar esses professores provendo-os com um mínimo de material e de apoio didático, a princípio, e com o programa do LOGOS II, posteriormente, foram buscas permanentes.

$\mathrm{Na}$ escola, o respeito que os alunos tinham pelos professores era significado nas relações pessoais existentes na comunidade, nas proximidades, nas vizinhanças, no contato direto entre professores e pais. O professor Vilson, ao falar da posição de professor, buscou na posição de pai para significar o trabalho realizado pelo aluno em casa e na escola. Ele, como professor e pai, iniciou falando sobre sua preferência em trabalhar na escola rural, uma vez que o aluno "tem mais vivência". Os sentidos que o professor estabelece para "vivência" estão relacionados à moradia no sítio, a uma pessoa que mora e conhece a terra. A "vivência" de alguém que saiba "fazer um serviço", por exemplo, o lanche da escola. Vem de "berço", diz o professor, para reforçar que essas experiências de vida vêm de casa, local em que os pais educam.

\begin{abstract}
Vilson: [...] sempre trabalhei em escola rural, gosto das escolas dos sítios, principalmente porque parece que a criança tem mais vivência. [A criança] Entende, ela trabalha, ela tem uma ocupação. Só que, por incrível que pareça, hoje em dia, conforme as leis, que se você vai verificar, o pai pede para um filho fazer um serviço, e existe a lei que diz que é serviço pesado, que esse serviço não é compatível com a criança. Então, naquela época, já existiam até algumas restrições da lei. Mas a criança já sabia, ela já vinha... aquilo ela trazia de berço. Então, ainda mais com o sistema que a gente montou, dentro da própria cozinha da escola, que os maiores faziam [o lanche], os pequenininhos somente acompanhavam visualmente.
\end{abstract}

Temos aqui um exemplo de heterogeneidade constitutiva do sujeito professor-pioneiro, em que o discurso do caráter do morador do sítio é passado para o caráter do aluno da escola. O mesmo princípio de que a criança deve ajudar em casa, limpar, cozinhar, lavar é levado para a escola do professor-pioneiro. Todos os alunos, na escola, ajudavam nessas tarefas. "Entende, ela trabalha, ela tem uma ocupação", a criança do sítio sabe trabalhar com o balde e o sabão, com o arroz e a panela. Na escola do professor-pioneiro, os alunos iam para a escola, meninos e meninas, e faziam as mesmas atividades de casa na escola. Significavam-se na escola os mesmos sentidos para o trabalho realizado em casa.

No discurso do trabalho infantil dentro de casa e na roça, na divisão das tarefas, meninos e meninas eram solicitados indistintamente. A interrupção dos estudos para exercer ocupações em casa fez com que muitos de nossos professores somente retornassem aos estudos mais tarde, quando jovens ou mesmo adultos. Na época em que se mudaram para Cláudia e iniciaram seu trabalho como professores, a grande maioria não tinha o $1^{\circ}$ grau completo. Esta separação entre estudo e trabalho em casa, quando o pai julgava e priorizava de acordo com o momento vivido em casa, com as quebras cronológicas no currículo escolar, fazia parte das práticas pedagógicas dos professores na escola do professor-pioneiro. Eles traziam essa experiência, quando não por experiência própria por conhecer esse contexto, e sabiam das consequências para o estudo que estas interrupções causavam. Conversar com os pais e empresários da região era uma prática dos professores, que faziam reuniões numa tentativa de reverter a evasão escolar investindo na qualificação dos alunos.

\footnotetext{
Roseli: Mas era muito... e depois a gente não perdia a oportunidade, que você ia lá na casa e conversava, e eles iam mesmo, sabe. [...] Olha, nós chegamos numa época que os alunos... tinha muito... e estava muito rebelde, assim muito terríveis de trabalhar. Porque teve um tempo que as serrarias pegavam as crianças para trabalhar. Podia menor [de idade] trabalhar, eu não sei até que ano que foi, mas... E a escola tinha muita dificuldade, que tinha evasão escolar, né, eles deixavam de ir na escola para ir trabalhar, porque ganhava dinheiro, né. Então tinha [que pedir ajuda] dos pais, dos madeireiros, para evitar, um pouco, a evasão.
}

Cristinne: Os pais eram analfabetos? Ou eram alfabetizados?

Roseli: A maioria [dos pais eram] analfabetos.

Na escola do professor-pioneiro, a convivência com a realidade da evasão escolar gerou outro discurso que influenciou na constituição das práticas pedagógicas dentro e fora da escola, "você ia lá na casa e conversava". Não bastava conversar somente com o aluno, era importante "ir na casa" do aluno, e conversar diretamente com "os pais. Essa prática envolvia outros sujeitos além dos constituídos no espaço institucional da escola, envolvia os pais e os donos das madeireiras. Os pais e madeireiros também se viam envolvidos na relação com os sujeitos do processo educacional, de ensino e aprendizagem, com os alunos e professores da escola. "Porque teve um tempo que as serrarias pegavam as crianças para trabalhar", e o 
trabalho das crianças era resultado da permissão dos pais e de uma proposta de inclusão infantil no trabalho das empresas.

Os alunos que saíam da escola para trabalhar nas madeireiras tinham como chamariz o salário ao final do mês. Entre o espaço escolar e a qualificação, por um lado, e o espaço industrial e o salário, por outro, a história da evasão se relaciona com os sentidos pré-construídos dos próprios professores que, em suas infâncias, tinham abandonado os estudos para trabalhar.

Os professores, ao interpretarem sua história, estabeleceram conexões entre seu passado e seu presente. $\mathrm{Na}$ relação do discurso presente com os discursos anteriores é que se verifica como os efeitos de sentido são produzidos, a memória discursiva - já ditos que possibilitam a significação do que se fala. Para Pêcheux (1999, p. 52),

[...] memória discursiva seria aquilo que, face a um texto que surge como acontecimento a ler, vem restabelecer os "implícitos" (quer dizer, mais tecnicamente, os pré-construídos, elementos citados e relatados, discursos-transversos etc.) de que sua leitura necessita: a condição do legível em relação ao próprio legível.

E na relação com os discursos-transversos, o dizer da professora Roseli sobre sua prática pedagógica nos aponta para um caminho outro - o de mudar esse real já dado (de alunos em situação de evasão) e buscar pela qualificação desse futuro profissional. A professora Roseli "não perdia a oportunidade" e, valorizando a qualificação de seus alunos, propunha um acordo para reverter a situação. Na discursividade sobre a evasão, a professora fala da posição-sujeito de professora, ela 'pode' falar. No discurso da evasão, as regras e rituais de dispositivos da educação escolar funcionam como dispositivos para regular os que estão dentro ou fora da escola, e a busca da inclusão daqueles que estão fora é uma constante, muitas vezes, como no relato da professora, entrando em contraste com os interesses dos madeireiros.

No mesmo recorte, a professora Roseli comenta que a maioria dos pais era analfabeta. Mesmo nestas condições, os pais participavam das atividades da escola e acompanhavam seus filhos durante seu aprendizado, principalmente conversando com os professores. É significativo que os pais não delegavam totalmente à escola a educação de seus filhos, uma vez que, nas entrevistas realizadas, os pais controlavam seus filhos em casa e esperavam dos professores a mesma atitude. "Vem de berço", diz o professor Vilson, que reproduz na escola as mesmas atitudes de um pai com seu filho. Diferente de "hoje", em que a escola "virou mais uma questão assistencial", explica o professor:

\begin{abstract}
Vilson: A sociedade toda se envolvia mais com a escola do que hoje. Porque hoje parece que a escola já perdeu aquele... aquele vínculo de trabalho dela. Ela virou mais uma questão assistencial [...]. [...] isso nos deixa bastante entristecidos, porque a sociedade, o pai e a mãe, praticamente enfim, eles não se preocupam mais com a escola.
\end{abstract}

Se agora os pais "não se preocupam mais com a escola", na escola do professor-pioneiro a proximidade entre eles era constante e se fazia pelo próprio enclausuramento em que as pessoas de Cláudia estavam. Esta proximidade social era resultado da afinidade produzida por serem imigrantes da mesma região. A maioria dos professores entrevistados veio do Estado do Paraná, das áreas agrícolas e tinha experiências de vida em comuns. E essas experiências geravam temas para as aulas, como nos conta a professora Aleixa Kowal de Prá:

\footnotetext{
Aleixa: Mas não foi assim tão difícil, porque a maioria daqui veio do Paraná, Rio Grande do Sul, Santa Catarina, né, e nós éramos muito próximos aos pais [dos alunos]. Esse contato da proximidade dos pais era muito bom. Porque a gente sentava para um cafezinho e aí, aonde a gente conseguia registrar, nas falas dos pais, ou do que eles gostavam, do que... e a forma em que eles viviam. Então, a gente ia readaptando as nossas, os nossos trabalhos [na escola], e foi assim, sabe.
}

Vimos anteriormente que, para Pêcheux, o sujeito é "colocado como autor em cada prática que se inscreve", o sujeito responde enquanto autor e se constitui como resultado de uma prática. No discurso pedagógico, ser professor era uma função que gerava prestígio social. Em uma sociedade em que a economia se baseava no extrativismo vegetal com o corte e venda da toras, na indústria representada pelo beneficiamento da madeira, pelo setor agrícola e pecuário, exercer atividade de professor era projetar-se na pirâmide social, movendo-se ao alto.

$\mathrm{Na}$ Análise de Discurso temos que a identidade é compreendida como uma construção discursiva. $\mathrm{O}$ professor-pioneiro construiu sua identidade a partir de seus discursos na sua relação com a sociedade e com as políticas públicas educacionais. O sujeito é considerado como na/da linguagem como uma construção histórica, social e ideológica. Segundo Coracini (2003, p. 198), a identidade é um "processo complexo e heterogêneo, do qual só é possível capturar momentos de identificação", uma vez que os sujeitos são efeitos de várias formações imaginárias. O sujeito se constitui ao significar (ORLANDI, 1998), e estes professores se identificaram como professores-pioneiros ao significarem-se dentro 
de dado contexto histórico na relação com os discursos circulantes.

\section{CONSIDERAÇÕES FINAIS}

Com o recorte temporal entre 1978 e 1988 estudamos o discurso produzido pelos professores-pioneiros sobre a escola estadual e municipal em Cláudia. Destacamos o efeito de sentidos da escola do professor-pioneiro como a escola construída e mantida pela comunidade, mostrando o empenho da população em abrir esse espaço junto às instâncias públicas para que a prática da escolarização se estabelecesse. Entendemos que os sentidos, quando estabelecidos, são constituídos a partir das constantes disputas pelos grupos sociais que, quando no poder, ora os estabelecem, ora os excluem. Construir e manter uma escola não era apenas visualizar o ato de contratar pedreiros para a construção, mas de um processo que requeria a participação de todos, desde o elenco de alunos e a seleção dos professores. Neste processo, estabelecia-se, dentro do próprio grupo social, um mutirão de participantes para construir o prédio, um mutirão para contratar o professor, um mutirão para colocar em funcionamento para, assim, se fazer a educação.

Neste mutirão de pessoas envolvidas é que se constituiu a posição-sujeito do professor, em seu discurso sobre o seu papel neste contexto de escolarização. Ser um professor-pioneiro não apenas como o primeiro a chegar, mas também como o professor que trabalha em uma escola em todos os momentos necessários, junto aos pais, com os empresários, separando materiais didáticos, avaliando os alunos e se autoavaliando. Este sujeito se constituiu como produto de uma série de filiações assumidas e sua movimentação por entre o contexto vivido. Em Pêcheux (2002, p. 56), "todo discurso é o índice potencial de uma agitação nas filiações sócio-históricas de identificação]" e neste mutirão de pessoas unidas em um ideal este sujeito-imigrante se identificou com o papel de sujeito-professor, discursando sobre si e sobre o outro, seu colega professor-pioneiro.

\section{REFERÊNCIAS}

COLONIZADORA SINOP S.A. Histórico da Gleba Celeste $-\mathbf{5}^{\mathrm{a}}$ parte: Cidade Cláudia. Sinop, s.d. 5 fls.

COLONIZADORA SINOP S.A. Plano de loteamento da Cidade Cláudia. Prefeitura Municipal de Sinop-MT. 10 fev. 1983. 7 fls.

CORACINI, Maria José(Org.). Identidade e discurso: (des)construindo subjetividades. Campinas: Unicamp; Chapecó: Argos Editora Universitária, 2003.

ELIAS, Norbert. O processo civilizador. Rio de Janeiro: Jorge Zahar, 1994. v. 1.

GUIMARÃES, Eduardo. Semântica do acontecimento: um estudo enunciativo da designação. Campinas: Pontes, 2002.
INDURSKY, Freda. Formação discursiva: ela ainda merece que lutemos por ela? In: SEMINÁRIO DE ESTUDOS EM ANÁLISE DO DISCURSO: mapeando conceitos, confrontando limites, 2., 2005, Porto Alegre. O campo da Análise do Discurso no Brasil: mapeando conceitos, confrontando limites, 2005. Disponível em: <www.discurso.ufrgs.br/sead2/doc/freda.pdf > Acesso em: 15 maio 2006.

MTNews. Cláudia. Disponível em: <www.mtnews.com.br/ cidades/claudia.htm>. Acesso em: 24 maio 2004.

MUTTI, Regina Maria Varini. Análise de discurso e ensino de português: o que interessa ao professor. Entrelinhas - a revista do Curso de Letras, Unisinos - Universidade do Vale do Rio dos Sinos, São Leopoldo, ano 2, n. 1, jan./abr. 2005. p. única. Disponível em: <http://www.entrelinhas.unisinos.br/index. php?e=1\&s=9\&a=5>. Acesso em: 16 ago. 2009 .

ORLANDI, Eni Pulcinelli. Identidade linguística escolar. In: SIGNORINI, Inês (Org.). Lingua(gem) e identidade: elementos para uma discussão no campo aplicado. Campinas: Mercado de Letras, 1998.

PÊCHEUX, Michel. Semântica e discurso: uma crítica à afirmação do óbvio. 2. ed. Campinas: Editora da Unicamp, 1995.

PÊCHEUX, Michel. Análise automática do discurso (AAD-69). In: GADET, Françoise; HAK, Tony (Org.). Por uma análise automática do discurso: uma introdução à obra de Michel Pêcheux. 3. ed. Campinas: Unicamp, 1997. p. 61-161.

PÊCHEUX, Michel. Papel da memória. In: ACHARD, Pierre et al. Papel da memória. Campinas: Pontes, 1999. p. 49-57.

PÊCHEUX, Michel. O Discurso: estrutura ou acontecimento. 3. ed. Campinas: Pontes, 2002.

SOUZA, Edison Antônio de. Sinop - história, imagens e relatos: um estudo sobre a sua colonização. Cuiabá: EdUFMT, 2004.

\section{Entrevistas}

MALDONADO, Roseli de Moura. Roseli de Moura Maldonado: depoimento. [06 jun. 2004]. Entrevistadora: Cristinne Leus Tomé. Cláudia, MT, 2004. 1 microcassete sonoro (1h41min56s). Regravado em 1 CD-ROM. Entrevista concedida para a Tese de Doutorado sobre a Educação de Cláudia-MT entre 1978 e 1988.

PRÁ, Aleixa Kowal de. Aleixa Kowal de Prá: depoimento. [06 jun. 2004]. Entrevistadora: Cristinne Leus Tomé. Cláudia, MT, 2004. 1 microcassete sonoro (1h41min24s). Regravado em 1 CD-ROM. Entrevista concedida para a Tese de Doutorado sobre a Educação de Cláudia-MT entre 1978 e 1988.

SANTOS, João Olegário dos. João Olegário dos Santos: depoimento. [12 mar. 2004]. Entrevistadora: Cristinne Leus Tomé. Cláudia, MT, 2004. 1 microcassete sonoro (1h17min15s). Regravado em 1 CD-ROM. Entrevista concedida para a Tese de Doutorado sobre a Educação de Cláudia-MT entre 1978 e 1988.

VOLLBRECHT, Vilson. Vilson Vollbrecht: depoimento. [29 fev. 2004]. Entrevistadora: Cristinne Leus Tomé. Cláudia, MT, 2004. 1 microcassete sonoro (1h07min33s). Regravado em 1 CD-ROM. Entrevista concedida para a Tese de Doutorado sobre a Educação de Cláudia-MT entre 1978 e 1988.

Artigo recebido em julho 2014.

Aprovado em novembro 2014. 